IZA DP No. 8754

Micro and Macro Determinants of Health: Older Immigrants in Europe

Amelie Constant

Teresa García-Muñoz

Shoshana Neuman

Tzahi Neuman

December 2014 


\title{
Micro and Macro Determinants of Health: Older Immigrants in Europe
}

\author{
Amelie Constant \\ George Washington University, Temple University and IZA \\ Teresa García-Muñoz \\ University of Granada \\ Shoshana Neuman \\ Bar-llan University, CEPR and IZA \\ Tzahi Neuman \\ Hadassah-Hebrew University Medical Center
}

Discussion Paper No. 8754

December 2014

\author{
IZA \\ P.O. Box 7240 \\ 53072 Bonn \\ Germany \\ Phone: $+49-228-3894-0$ \\ Fax: +49-228-3894-180 \\ E-mail: iza@iza.org
}

\begin{abstract}
Any opinions expressed here are those of the author(s) and not those of IZA. Research published in this series may include views on policy, but the institute itself takes no institutional policy positions. The IZA research network is committed to the IZA Guiding Principles of Research Integrity.

The Institute for the Study of Labor (IZA) in Bonn is a local and virtual international research center and a place of communication between science, politics and business. IZA is an independent nonprofit organization supported by Deutsche Post Foundation. The center is associated with the University of Bonn and offers a stimulating research environment through its international network, workshops and conferences, data service, project support, research visits and doctoral program. IZA engages in (i) original and internationally competitive research in all fields of labor economics, (ii) development of policy concepts, and (iii) dissemination of research results and concepts to the interested public.
\end{abstract}

IZA Discussion Papers often represent preliminary work and are circulated to encourage discussion. Citation of such a paper should account for its provisional character. A revised version may be available directly from the author. 
IZA Discussion Paper No. 8754

December 2014

\section{ABSTRACT \\ Micro and Macro Determinants of Health: Older Immigrants in Europe ${ }^{*}$}

We study the health determinants of immigrant men and women over the age of fifty, in Europe, and compare them to natives. We utilize the unique Survey of Health Aging and Retirement (SHARE) and augmented it with macroeconomic information on the 22 home countries and 16 host countries. Using Multilevel Analysis we can best capture the within and between countries variation and produce reliable results. We find that during the first decade after arrival, immigrants report higher levels of subjective health compared to natives and to previous cohorts of immigrants. As time since migration passes by, reported subjective health decreases; immigrants' health becomes the same as that of comparable natives or it even decreases. The level of economic development of both the origin and the host country positively affect the individual's health, but the effect of the host country is much more pronounced. It appears that positive and negative deviations (of the host from the origin country) have different impacts on individual health: an increase in a positive deviation (the country of origin is more developed compared to the host country - a 'loss' for the immigrating individual) leads to a decrease in the immigrant's subjective health, while an increase in the absolute negative deviation (a 'gain' for the immigrating person) leads to an increase in the immigrant's subjective health. These differential effects can be explained as some variant of the Loss-Aversion Theory.

JEL Classification: $\quad \mathrm{C} 22, \mathrm{J11}, \mathrm{J12}, \mathrm{J} 14, \mathrm{O} 12, \mathrm{O} 15, \mathrm{O} 52$

Keywords: $\quad$ self-assessed health status, immigration, Europe, country of origin, older population, multilevel regression

Corresponding author:

Amelie F. Constant

1737 Chestnut Street

Suite 900

Philadelphia, PA 19103

USA

E-mail: Constant@iza.org

\footnotetext{
*We are thankful to participants in the $11^{\text {th }} \mathrm{AM}^{2}$ Workshop (Bonn, May 30 - June 1,2014 ) and Corrado

Giulietti for helpful comments on an earlier version of the paper.
} 


\section{Introduction}

Immigrants constitute a major feature in many countries in terms of numbers, growth rates, and cultural differences. The United Nations (2013) report that between 1990 and 2013 the total number of migrants in the world increased by 49.2 percent: from 155.5 in 1990 to 232 in 2013. In 2013, Europe hosted 72 million migrants, constituting 31 percent of the world migrants' stock. Besides the US that hosts 45.8 million migrants, five European countries are on the list of the ten largest immigrant absorbing countries: Russia (11 million), Germany (9.8 million), France (7.4 million), Britain (7.8 million), and Spain (6.5 million) (United Nations, 2013). ${ }^{1}$ In addition, the non-European foreign-born population in the European Union (EU) on January $1^{\text {st }}, 2013$ was 33.5 million. Another 17.3 million persons were born in a different EU Member State than the one they were living in (http://epp.eurostat.ec.europa.eu/statistics_explained/index.php/Migration and migrant population statistics).

As natives age in the host country, so do the immigrants. In Europe, the share of older immigrants is growing fast, as earlier cohorts of immigrants age, younger arrivals bring their older parents to live with them, and more skilled immigrants migrate later in life. On January $1^{\text {st }}, 2013$, the median age of the EU population was 42 years. For immigrants (in 2012) it varied from 26 years in the UK to 40 years in Bulgaria (http://epp.eurostat.ec.europa.eu/statistics_explained/index.php/Migration_and_migrant_po pulation statistics). About 30 percent of the immigrants in Europe belong to the age group of 50+. The parallel figure for the US is somewhat higher, at 33.8 percent (United Nations, 2013). This warrants a study about the middle-aged and beyond population.

As health starts deteriorating around the age of 50, studying the health of older immigrants is essential and of great socio-political importance. It can "potentially offer some significant analytical advantages for understanding the origins of health disparities in any population" (Jasso et al., 2004, p. 1) and allow us to better address public health challenges. A better understanding of the immigrants' health status, behavior, and attitudes is needed in order to better cater to their needs and integration. Compromised health statuses and unhealthy behaviors can have consequences burdening the health care and

\footnotetext{
${ }^{1}$ The other four are: Saudi-Arabia (9.1 million), the Union of Arab Emirates (7.8 million), Canada (7.3 million), and Australia (5.6 million).
} 
welfare systems of the host countries. Equally important is to understand whether the health status of immigrants changes with additional time spent in the host country and whether it is different than that of comparable natives.

While health is a good measure of the quality of the labor force and the well-being of a population in general and while it is of outmost relevance to policymakers in the private and public sectors, it has not received the proper research interest among economists. Human capital theory offers predictions about the health selection of emigrants: they may be positively or negatively selected compared to their compatriots left behind. Emigrants are more likely to have a positive and optimistic stance about their future, which correlates with good health. In addition, the health selection criteria of the host countries, ${ }^{2}$ and the fact that migrants survive the stress of moving, makes it more likely that economic immigrants are positively self-selected with respect to health. Empirical studies provide evidence for these predictions (Jasso et al., 2004; Neuman, 2014). On the other hand, there is no sound theory that predicts the health status of immigrants compared to natives in the host country. Arriving migrants may be more, less or equally healthy than the natives. Their health status during their residence in the host country can change and approach or diverge from that of natives. It is therefore an empirical challenge.

Immigrants offer an interesting case-study because they are confronted with at least two reference-points; namely their countries of origin and the host countries. Their health status upon arrival can provide valuable insights into selection issues and their permanency in the new society can explain if there is health assimilation with time in the host country.

Immigration also serves as an experimental framework for the testing of the effects of environmental factors on diseases and on ethnic health disparities. By definition, when migrants move from one environment with one set of health risks/behaviors/constraints into another that may contain a quite different mix, they change regimes. Since isolating meaningful variation in health environments may be problematic within a domestic native population, scholars from various disciplines have been eager to use immigrant samples to measure the impact that environmental factors (such as diets, environmental risks, health care systems, political unrest) may have on health (Jasso et al., 2004).

\footnotetext{
${ }^{2}$ An exception is Israel, where immigrants are not screened for health problems. Migrants going to Israel are largely motivated by national motives rather than by economic incentives (Neuman, 2005).
} 
Epidemiology has a long tradition in using migrant patients to isolate environmental effects on diseases. A typical epidemiological study examines some health outcome in three populations that presumably differ in a significant way in their environments: individuals in the sending country, natives in the host country, and migrants. The basic idea is that if disease rates change when one moves from one place to another, then this indicates the role of environmental factors (Kasl and Berkman, 1983; Marmot, Adelstein and Bulusu, 1984).

Most studies find a "healthy immigrant effect", in which, immigrants are healthier than natives when they first arrive in the new country but their health status deteriorates the longer they stay in the new country and assimilate to the health level of natives (Antecol and Bedard, 2006; Chiswick et al., 2008; Giuntella and Mazzonna, 2014; Courbage and Khlat, 1996; Delaney et. al., 2013; Carrasco-Garrido et al., 2007). Immigrants in the US are also healthier than their socio-economic status would predict (Jasso et al., 2004; Ronellenfitsch and Razum, 2004).

In this paper we take advantage of the incredibly rich Survey of Health Aging and Retirement Europe (SHARE) that covers individuals over 50 in most European countries. We pool the three existing waves of 2004/5, 2006/7 and 2011 and supplement this survey with country-specific macro-data on the sending and receiving countries. We explore the full spectrum of the self-assessed health status (SAHS), as numerous studies have indicated that self-ratings of health are good predictors of mortality and morbidity even more than medical records (Idler and Benyamini, 1997; Mora et al., 2008; Cesari et al., 2009). We include a battery of health variables, as well as behavioral, demographic, and socioeconomic variables to best estimate SAHS. Because individuals are clustered within countries, we use multilevel analysis that is the most appropriate technique to analyze within- and between-country variation. A careful analysis is conducted to provide answers to our questions: what are the determinants of the individuals' SAHS; do immigrants differ from natives in their SAHS; how does SAHS change with duration in the host country and among different immigrant groups? These questions have not been studied in-depth for Europe. Our novelty is the econometric technique and the inclusion of macro-economic characteristics of the home and host countries.

The paper is structured as follows: the next section presents an overview of the immigrant populations in Europe, the history of immigration and their current health levels. 
Section 3 reviews the relevant literature identifying gaps and oversights. Section 4 describes the data and the sample. Section 5 outlines the empirical methods and hypotheses. Section 6 presents the results and Section 7 concludes.

\section{Europe and its Immigrant Populations}

In the late 1950s, the European Union (EU) was created by the following original member states: Belgium, France, Germany, Italy, Luxembourg, and the Netherlands. In the 1970s, Denmark, Ireland, and the UK joined in. Greece, Spain and Portugal joined in the 1980s, and Austria, Finland and Sweden in the 1990s, creating the "Old EU15". The first EU enlargement to the eastern countries in 2004 embraced the EU10 (Cyprus, the Czech Republic, Estonia, Hungary, Latvia, Lithuania, Malta, Poland, Slovakia, and Slovenia). Bulgaria and Romania joined the EU25 in 2007. With the accession of Croatia in 2013, the EU is now a union of 28 countries.

By the mid- $20^{\text {th }}$ century, Europe was an immigration continent. Economic migrants in Europe can be grouped into the following general categories: (i) guest-workers from the less developed Southern-European and North-African countries such as Greece, Italy, Spain, Portugal, Morocco, the former Yugoslavia and Turkey, who were joined by their families later on. While Germany, Austria, and Switzerland recruited most of the guestworkers, countries such as Denmark, the Netherlands and France also recruited guestworkers; (ii) citizens from the former colonies of European countries such as England, France, Spain, Portugal and the Netherlands - in North- and West-Africa, and in South- and Southeast-Asia; (iii) migrants from the former Soviet Union and Eastern Europe after the collapse of communism in 1989; (iv) Many refugees, asylum seekers and irregular migrants also came to Europe from less privileged regions that suffer from famines, wars, political violence and geo-political shifts.

The heterogeneity of the countries of origin in terms of economic development, market structures, educational systems, technological and innovation levels, and proximity to the destination countries led to large variations in educational attainments, occupational outcomes and wages of immigrants in Europe. Similarly, heterogeneity with respect to religion and culture can influence the health behaviors and the overall health-status of immigrants. For example, some cultures do not allow the consumption of liquor, wine or 
cigarettes, decreasing the chances of finding alcoholics and smokers among them. Other cultures emphasize diets rich in fruits, vegetables and fish that minimize obesity among their members. Therefore, we expect wide variations in the health of immigrants in Europe.

More detailed country-specific information about the foreign-born populations in Europe (for 2010) can be gained from Table 1. As Table 1 indicates, immigrants comprise more than 10 percent of the local population in a large number of European countries. At the top ranks we find Luxembourg (32.5 percent of the population are immigrants), followed by Cyprus (18.8 percent) and Estonia (16.3 percent). The share of immigrants is below 5 percent in only a few countries; Slovakia ranks last with immigrants comprising only 0.9 percent of the total population. The majority of immigrants were born in nonEuropean countries. Moreover, given that most European countries are facing dramatic drops in fertility among natives, ${ }^{3}$ and given that immigrants in Europe have significantly higher fertility rates, ${ }^{4}$ it is expected that the shares of immigrants will keep growing.

Table 1: Foreign-born populations in European countries, 2010

\begin{tabular}{lrrr}
\hline Country & $\begin{array}{r}\text { Number of } \\
\text { foreign-born }\end{array}$ & Share of foreign-born & $\begin{array}{r}\text { Share of non-European } \\
\text { foreign-born }^{2}\end{array}$ \\
\hline Austria & $1,276.0$ & 15.2 & 9.1 \\
Belgium & $1,503.8$ & 13.9 & 7.0 \\
Cyprus & 150.7 & 18.8 & 13.5 \\
The Czech Republic & 398.5 & 3.8 & 2.6 \\
Denmark & 500.8 & 9.0 & 6.3 \\
Estonia & 217.9 & 16.3 & 15.0 \\
Finland & 228.5 & 4.3 & 2.8 \\
France & $7,196.5$ & 11.1 & 7.8 \\
Germany & $9,812.3$ & 12.0 & 7.8 \\
Greece & 125.6 & 11.1 & 8.3 \\
Hungary & 436.6 & 4.4 & 1.4 \\
Iceland & 35.1 & 11.0 & 3.7 \\
Ireland & 565.6 & 12.7 & 2.9 \\
Italy & $4,798.7$ & 8.0 & 5.3 \\
Latvia & 343.3 & 15.3 & 13.6 \\
\hline
\end{tabular}

${ }^{3}$ The most pronounced changes are evidenced in the European Catholic countries: Ireland (from 3.8 in the early 1970 s to 2.1 in 2010), Spain (from 2.2 in the early 1980 s to 1.4 in 2010), Portugal (from 3.0 in the early 1970s to 1.4 in 2010), Italy (from 2.4 in 1970 to 1.4 in 2009), and Poland (from 2.1 in 1990 to 1.4 in 2010) (Eurostat, 2013).

${ }^{4}$ For example, in Spain, in 2009, while the number of births per 1000 native women in fertility age, was 9.7, it was 17.8 within the foreign population (National Institute for Statistics-INE, Spain); in the UK, in 2010, the Total Fertility Rate (TFR) of UK-born mothers was 1.88, versus 2.45 for non-UK-born mothers (Office for National Statistics-ONS, UK). 


\begin{tabular}{lrrr}
\hline Country & $\begin{array}{r}\text { Number of } \\
\text { foreign-born }\end{array}$ & Share of foreign-born ${ }^{2}$ & $\begin{array}{r}\text { Share of non-European } \\
\text { foreign-born }^{2}\end{array}$ \\
\hline Luxembourg & 163.1 & 32.5 & 5.6 \\
The Netherlands & $1,832.5$ & 11.1 & 8.5 \\
Norway & 524.6 & 10.8 & 6.5 \\
Poland & 456.4 & 1.2 & 0.7 \\
Portugal & 793.1 & 7.5 & 5.7 \\
Slovakia & 50.4 & 0.9 & 0.4 \\
Slovenia & 253.8 & 12.4 & 11.0 \\
Spain & $6,442.8$ & 14.0 & 8.9 \\
Sweden & $1,337.2$ & 14.3 & 9.2 \\
The UK & $7,012.4$ & 11.3 & 7.7 \\
\hline
\end{tabular}

${ }^{1}$ In $1,000 \mathrm{~s} ;{ }^{2}$ As percent of the total population

Source: Eurostat, 2010 (online data access: tps00178, migr_pop3ctb)

Notes: Data are not available for Bulgaria, Croatia, Switzerland and Ukraine; The Slovakian data are for the year 2009; The Belgian data are provisional.

The religious landscape in Europe is also expected to change, due to the large share of Moslem immigrants in most EU countries. According to the Pew Research Center (2011), the Moslem share in the European population as a whole is expected to grow by nearly one-third over the next 20 years, rising from 6 percent of the region's population in 2010, to 8 percent in 2030 .

The share of the 50+ sub-population in Europe is constantly growing in virtually all countries. Figure 1 shows that within a decade (from 2002 to 2012) the number of elder individuals increased by 116 percent.

Figure 1: Size of population aged 50 and over, Europe

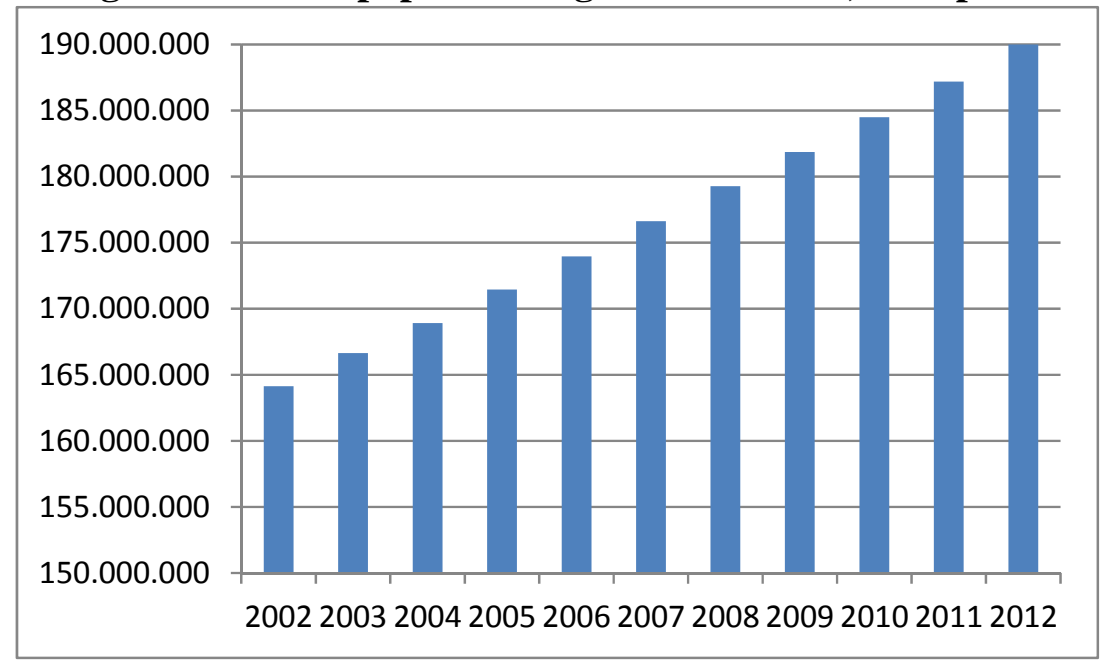

Source: Eurostat (2013) 


\section{Relevant Literature}

An extensive body of research related to immigrants in a variety of countries (Antecol and Bedard, 2006 - for the US; Chiswick et al., 2008 and Biddle et al., 2007- for Australia; Kennedy et al., 2006 - for Canada; Giuntella and Mazzonna, 2014 - for Germany; Klaht and Courbage, 1996 - for Moroccans in France; Delaney et. al., 2013 - for recent Irish immigrants in the UK; Carrasco-Garrido et al., 2007 - for Spain) has documented that upon arrival in the host country immigrants are healthier than natives; they are also healthier than their compatriots remaining in their countries of origin. This phenomenon has been termed the "healthy immigrant effect" (HIE). The immigrant health advantage appears to be prevalent also at older ages (Markides, Salinas and Sheffield, 2008/9). ${ }^{5}$ However, the initial advantage deteriorates with time spent in the receiving countries and converges toward the native-born populations; sometimes it even goes below the natives. ${ }^{6}$ The decline in health is more pronounced when considering the over-time improvement in immigrants' socio-economic status (Jasso et al., 2004; Ronellenfitsch and Razum, 2004; Guintella, 2013; Guintella and Mazzonna, 2014; Neuman, 2014).

Several explanations for the health advantage upon arrival have been suggested: (i) positive self-selection - there is a consensus that the initial health advantage is the result of migrants' positive-selection. This theory posits that only the healthiest and most motivated individuals choose to undergo the traumatic experience of migration to a new country while people who are sicker and weaker stay behind (Bentham, 1988; Jasso et al., 2004; Palloni and Ewbank, 2004); (ii) another theory is that medical examinations by immigration authorities in the host countries further screen out less healthy immigrants at the border. Screening started in the US in 1887 when the Marine Hospital Service facility was established in Staten Island in response to fear of diseases such as yellow fever, cholera and tuberculosis. One hundred years later, another dread disease, AIDS, thought to be related to immigrants (Evans, 1987). The health screening of immigrants is still the norm in Australia, Canada, and other countries. In Australia, immigration is viewed "as a selective

\footnotetext{
${ }^{5}$ The authors provide evidence for older immigrants ( 65 or older) in the US, who compose 11 percent of the total American immigrant population.

${ }^{6}$ Linking immigrant obesity and labor market outcomes, Averett et al. (2012) find evidence of the HIE and show that as immigrants' weights increase with time in the UK men face a wage penalty and are less likely to work in a white collar job; overweight immigrant women are substantially more likely to suffer work limitations.
} 
process whereby those who do not meet certain health requirements are not granted visas to migrate" (VandenHeuvel and Wooden, 1999, p. 94). However, health screening blocks only a small share of immigrants; (iii) a third theory is that diets and behaviors are healthier in the home country, including better nutrition and dietary habits, more physical activity, close family and religious ties, and other socially protective factors (Marmot and Syme, 1976; Antecol and Bedard, 2006; Biddle, Kennedy and McDonald, 2007); and (iv) finally, it may be that self-reported health conditions are under-reported by the foreign-born, either because they have not yet been diagnosed, or because of differences in perceptions about health status (Jasso et al., 2004).

It should be also noted, however, that other studies do not find the HIE.

For studies related to immigration and health, Israel serves as an important research laboratory (Kasl and Berkman, 1983; Jasso et al., 2004), given its modern migration history with large numbers of migrants from diverse cultures (Europe, Asia and Africa). Interestingly, immigration to Israel is largely motivated by national motives rather than by economic incentives (Neuman, 2005) and immigrants are not screened for health problems. Immigrant health results may therefore not be tainted by selection hurdles.

Researchers are still puzzled about the possible explanations for the subsequent health deterioration of immigrants, and have offered several explanations: (i) most studies emphasize the role of "negative acculturation" through worsening of dietary styles, adoption of risky behaviors (smoking, alcohol consumption, overeating, lack of physical exercise), and erosion of social and cultural protective factors such as close family and religion ties and social solidarity and stability (Jasso et al., 2004; Acevedo-Garcia et al., 2005; Abraido-Lanza et al., 2005; Lara et al., 2005; Antecol and Bedard, 2006; Fenelon, 2013); (ii) another hypothesis is that immigrants tend to use healthcare services less frequently than natives, terminate treatment early, and receive lower quality healthcare. Disparities in use of healthcare services between immigrants and natives could stem from differences in health insurance coverage, poor knowledge of their rights, and difficulty communicating with health practitioners because of linguistic and cultural barriers (Antecol and Bedard, 2006; Biddle et al., 2007); (iii) structural theories based on historical, political, and economic contexts of immigration provide additional explanations for the worsening of 
immigrants' health over time; they are related to discrimination from xenophobia, racism, and "otherness" (Lara et al., 2005; Grove and Zwi, 2006; Viruell-Fuentes, 2007).

The poor working conditions of immigrants have been suggested as a significant contributor to the deterioration of immigrants' health as the fourth explanation. The hypothesis is that the sorting of immigrants into more dangerous and strenuous occupations, can lead to work-related injuries and fatalities and other health problems and explain the observed deterioration of their health. Moreover, as immigration increases the supply of healthy low-skilled workers, it also leads to a shift of natives towards better working conditions, thereby improving natives' health. Supportive evidence for this labormarket oriented theory is provided by Giuntella and Mazzonna (2014) for Germany and Orrenius and Zavodny (2009) and Zavodny (2014) for the US, where the jobs held by immigrants are more risky and physically arduous than the jobs held by US natives, leading to work-related health problems. ${ }^{7}$

While there are numerous empirical studies on migration and health outcomes, and in particular on the two leading themes of (i) health selectivity of international migrants; and (ii) the impact of migration on the subsequent health trajectory of migrants; more theoretical guidance is needed to fill the gap between evidence and theory. The contribution of theoretical models to the understanding of interactions between migration and health is remarkably small. Among the few theoretical models proposed in the literature are: "a migration model of initial health selectivity" and "a migration model of subsequent health trajectory" presented in Jasso et al. (2004), and a model of "health transmission" that attempts to describe the channels of deterioration of immigrants' health (Guintella, 2013).

Different health metrics are used for the examination of the immigrant-native health disparities. Following the literature on subjective-well-being, we use the self-assessed health status (SAHS) (Newbold, 2005; Garcia-Munoz, Neuman and Neuman, 2014b). SAHS has increasingly become a common measure of health in empirical research. A person's own understanding of her/his health is the 'internal' view of health, as opposed to 'external' views that are based on observations of doctors or pathologists (Sen, 2002). The belief that the individual is the best evaluator of her/his health status was supported by the

\footnotetext{
${ }^{7}$ Orrenius and Zavodny (2013) provide an excellent review of the literature showing that immigrants hold 'three-D' jobs: dirty, dangerous and difficult.
} 
findings of numerous studies, which indicated that self-ratings of health are good predictors of mortality and morbidity even more than medical records (Mossey and Shapiro, 1982; Idler and Benyamini, 1997; Cesari et al., 2009). Over 200 studies have reported robust correlations of self-assessments of heath and mortality and morbidity (Mora et al., 2008). The respondents in the above cited sample surveys are heterogeneous in terms of: country of residence, socio-economic status, race, ethnicity, education, preventive practices, and health conditions - indicating the universality of the phenomenon. Accordingly, questions on subjective-health were recently introduced in questionnaires used within the social sciences and the medical professions. Furthermore, SAHS has distinct advantages in evaluations of immigrants' health: immigrants may be misdiagnosed by host country medical doctors due to cultural and language barriers, or because native doctors may not be familiar with specific medical or psychosomatic conditions that are occurring in foreign countries. Consequently, it appears that SAHS is a good measure for native-immigrant comparisons.

Other measures of health include: mortality rates, life expectancy, disability measures, number of physical and cognitive functioning limitations, being diagnosed with a specific health problem/disease, overweight (measured by the Body-Mass-Index - BMI), number of hospital visits per period of time, and satisfaction with health. The first and second measures relate to the health-status of the community, while the others are individual measures. Disparities between immigrants and the native populations may differ across the various dimensions of health.

Observed health differences between native-born and immigrants could also vary by country of study and country of origin, and also by gender (Sole-Auro and Crimmins, 2008). We control for these aggregates in the regression analyses. When a pooled sample of host countries is employed - differences in aggregate measures of the receiving countries can be controlled for by adding aggregate country-level measures (such as, per-capita GDP, health expenditures, life expectancy and the Human Development Index - HDI). The coefficients of these country-specific variables also contribute to our understanding of how aggregate macroeconomic dimensions affect the immigrant's perceived-health, above and 
beyond the micro, medical and socio-economic determinants. ${ }^{8}$ Aggregate measures of the sending countries can also be added to further understand the factors behind perceived health of immigrants.

The macroeconomic factors of the two reference countries (origin and host) have been included in a recent study that evaluates the determinants of immigrants' subjectivewell-being (SWB). Akay, Bargain and Zimmermann (2013) examined whether SWB of migrants in Germany is responsive to fluctuations in macroeconomic conditions in their countries of origin and in the regions where they live in Germany. They found that while immigrants in Germany are positively affected by the performances of the region in which they live (the local macros), they are negatively affected by macros of their countries of origin (migrants' well-being responds negatively to increases in GDP and positively to increases in unemployment in the country of origin).

Most studies use cross-sections for the statistical analysis. In the case of the immigrant population, however, this might create serious selection-biases. Besides the nonidentification of age-cohorts-period effects, the immigrant sample represents only those who remained in the receiving country; migrants who have died or returned to their home country are not represented. Return-migrants could include those who become sick and return to the home country, known as the "salmon-bias effect" (Sole-Auro and Crimmins, 2008). This effect could explain some unexpected findings such as lower mortality rates among foreign-born Mexicans than among natives in the US (Palloni and Arrias, 2004).

\section{Data and Descriptive Statistics}

\subsection{The dataset}

We utilize the Survey of Health, Aging and Retirement in Europe (SHARE), a unique European database that is the outcome of a collaborative effort of more than 150

\footnotetext{
${ }^{8}$ In an attempt to better understand aggregate population SAHS, Garcia-Muñoz, Neuman and Neuman (2014a, 2014b) included country-specific macroeconomic measures and found clear evidence that aggregate country SAHS are affected by macros such as per-capita GDP, expenditures on health, Human Development Index (HDI), the share of obese people and the share of active smokers. It follows that the country macros serve as some reference point when evaluation of individual SAHS takes place, ceteris paribus; higher levels of 'positive' macro measures such as GDP and HDI lead to more favorable individual SAHS, while larger 'negative' macros (obesity, smoking) result in lower individual SAHS. Another possibility is that the macros are proxy variables for country-level conditions that affect the individual SAHS. For instance, higher levels of per-capita GDP or of HDI could indicate better nutrition and higher quality of health-services.
} 
researchers world-wide, organized in multidisciplinary national teams and cross-national working groups. SHARE is patterned after the Health and Retirement Study (HRS) in the US. A scientific monitoring board and a network of advisors help to maintain and improve the project's scientific standards. The main funding comes from the European Commission $\left(5^{\text {th }}, 6^{\text {th }}\right.$ and $7^{\text {th }}$ framework programs).

There are three waves and one wave with retrospective information (SHARELIFE). The first wave was collected in 2004/2005, the second in 2006/2007, and the fourth mainly in 2011. The third wave, SHARELIFE, was collected in 2008/2009. While 19 countries participated in SHARE, not all countries were part of each wave. Moreover, the timing of data collection differs between countries (http://www.share-project.org/group-faq/faqs.

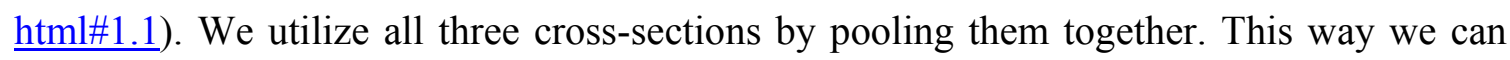
adequately address the age-period-cohort effects that cannot be identified in one crosssection and can bias the results for immigrants.

SHARE is an ideal dataset for the exploration of the full spectrum of factors behind SAHS for both natives and immigrants. It has a battery of micro data on health, socioeconomic status and social and family networks of more than 86,000 individuals aged 50 or over (and their partners). They are a balanced representation of the various regions in Europe, ranging from the Scandinavian countries (Denmark and Sweden), to Central Europe (Austria, France, Germany, Switzerland, Belgium, the Czech Republic and the Netherlands), to Eastern Europe (Poland, Hungary, the Slovak Republic and Estonia) and the South (Spain, Italy and Portugal).

The dataset contains detailed information on health, beyond the self-reported health, such as: health conditions, physical and cognitive functioning, health behavior, use of health-care facilities, diagnosis of diseases, and height; on behavioral health-risk variables such as: smoking, alcohol consumption, and over-weight; on economic variables such as: current work activity, wealth and consumption, old-age pension, and education; and on social variables and demographics such as: marital status, number of children in the household, mother and father alive, immigration status, years since migration and country of origin of migrants.

Our sample includes 16 European countries and complete records on both immigrants and natives and both men and women. It is composed of 43,037 natives 46.1 
percent of whom are men and 4,275 immigrants with male a share of 42.7 percent. Immigrants in the sample come from 22 different countries. We augment the SHARE data with country of origin and receiving country macroeconomic variables such as the percapita Gross Domestic Product (GDP).

\subsection{Variables and Hypotheses}

Our dependent variable is the respondent's subjective assessment of her/his healthstatus (SAHS), ranging from 1 (very poor) to 5 (excellent). This variable is constructed from a response to the question: "On a scale from 1 to 5 , where 1 describes the worst imaginable condition and 5 the best imaginable condition, how do you rate your health in general?"

The independent variables include the immigrant status, indicated by the yearssince-migration (YSM) variable. According to the immigrant assimilation literature, the coefficient of YSM comprises the extent and speed at which immigrants adapt to the new environment and it gages assimilation beyond the aging effect. YSM captures the exposure of immigrants to social and cultural norms or certain social influences to their health by the fact that they live in the host country and mingle with natives. We use a non-linear form of YSM because additional years of residence in the host country may have a differential effect on health. YSM is thus a categorical variable with three levels: (i) less than 10 YSM, the reference category; (ii) 11-20 YSM; (iii) more than 20 YSM. Note that in the analysis of the entire sample of natives and immigrants, natives are the reference group.

As individuals age, their health deteriorates according to biological and physiological changes. We capture the age affects by including age as a categorical variable for possible non-linear effects: (i) 61-70 years of age; (ii) 71-80 years; (iii) 81 years and over; with the reference group being 50-60. The health of immigrants, however, can also be influenced by events or shocks that occurred in the past, beyond changes due to aging. These are the cohort effects. For example, if a cohort endured famine or chemical weapons or other environmental factors their health may be compromised more or differently than another cohort. In addition, these factors may affect the process of their aging. We control for cohort effects by including eight dummy variables for decades of arrival: (i) 1900-1940; 
(ii) 1941-1950; (iii) 1951-1960; (iv) 1961-1970; (v) 1971-1980; (vi) 1981-1990; (vii) 19912000; and (viii) 20012010. The most recent arrivals are the reference group.

Period of interview effects or contemporaneous influences are important because they can affect the health of all age groups simultaneously, above and beyond normal aging. These effects can be economic crises or technological breakthroughs that occur in the host country during the residence of immigrants. While we control for period effects with dummies for each year of interview, we also make the assumption that these effects have the same impact on natives and immigrants. The reference category is 2004/5, which is the first wave. In the immigrant sample specification, we also control for country of origin. Due to small sample sizes by country of origin, we grouped countries together as best they fit by region and include the appropriate dummy variables.

Our data do not allow us to control for attrition in the sample due to selective return migration. Theoretically, immigrants who returned to their country before each interview year could be more or less healthy than the immigrants who stayed and are in our sample. We believe that selective return migration with respect to health is minimal in our data for the following reasons. First, all EU countries offer health care to all individuals, and health care in EU is better than in the countries of origin. Therefore, both more or less healthy immigrants will have an incentive to stay in the host countries. Second, we are looking at a sample of older immigrants who have been in the country for quite some time. Return migration usually occurs within the first five years since arrival and while immigrants are young. Lastly, the severe economic and financial crisis of 2008-2010 in Europe is more likely to have deterred older immigrants from returning because the countries of origin have been hit by the crisis even more.

The level of economic growth of a country has a strong impact on the health of its residents. To capture this influence on SAHS we include the logarithm of per capita GDP for the country of origin and for the receiving country. Another specification uses two continuous variables for the difference between home and host GDPs: a positive difference between origin and receiving GDPs and (absolute) negative difference between origin and receiving GDPs. The first one is equal to the difference between origin and receiving GDPs (logarithm) if this difference is positive, and zero otherwise. The second one is equal to the 
absolute value of the difference between origin and receiving GDPs (logarithm) if this difference is negative, and zero otherwise.

We include the height of the individual, which is fixed upon arrival and does not change with duration in the host country. Younger individuals are taller than their parents and as they arrive in different years we may see a difference in their SAHS. At the same time, height also denotes the prosperous upbringing of children; it is known that better nutrition results in taller bodies.

Our demographic variables include gender (a dummy variable that is set to 1 for male respondents), marital status (two categorical variables for married and widowed, with the reference group including divorced, separated and single respondents), and number of children in the household. We expect to find that respondents with children are healthier because they enjoy more care and support from family members.

Regarding socio-economic variables we control for income, using the income variable that is created by SHARE. It refers to the respondents' household income centiles; the higher the centile in which a household belongs, the higher the household income is. Unfortunately, we cannot control for education because this information does not exist in the first wave. However, since education correlates with socioeconomic status, income can also be viewed as a proxy for education.

The set of personal medical variables includes: (i) a set of dummy variables that relate to diseases that the individual is diagnosed with such as heart diseases, hypertension, vascular diseases, diabetes, lung diseases, arthritis, osteoporosis and cancer; (ii) health symptoms: a continuous variable that is the sum of different symptoms that the individual suffered from during the last 6 months, such as, sleeping problems, falling down, persistent cough, fatigue, swollen leg, and dizziness; (iii) drug use: a continuous variable that is the number of different drugs that the respondent takes at least once a week, such as, drugs for high-cholesterol, high blood-pressure, joint pain, back pain, sleep problems, anxiety or depression, and stomach burns; (iv) medical consultation: a continuous variable that is the response to the question: "During the last 12 months, about how many times in total have you seen or talked to a medical doctor about your health. Please exclude dentist visits and hospital stays, but include emergency rooms and outpatient clinic visits"; (v) hospitalization: a dummy variable that equals 1 if the respondent answered positively the 
question: "During the last 12 months, have you been in hospital overnight? Please consider stays in medical, surgical, psychiatric or any other specialized wards"; (vi) eyesight: a continuous variable ranging from 1 (poor) to 5 (excellent). It is the average of two variables related to eyesight that are the responses to the question: "Your distance/reading eyesight is: poor (1)...excellent (5)."

The set of behavioral variables includes (i) alcohol use: a dummy variable created from the answer to the question: "During the last 3 months, how often (during a standard week) have you drunk any alcoholic beverages, like beer, wine, spirits or cocktails?” The seven options range from 'not at all' to 'almost every day'. It equals 1 if the respondent drinks at least 5 days a week; (ii) smoking: a dummy variable that is set to 1 for respondents who smoke at the time of the survey; (iii) obesity is a dummy variable that is equal to 1 if the Body Mass Index (BMI) is greater than 30 .

We are using the SHARE-created variable, 'mobility', which pertains to the functional capacity of the individual, indicated by: walking 100 meters, walking across a room, climbing several flights of stairs, and climbing one flight of stairs. Mobility is an index in the range of $0-4$; a higher index value indicates more difficulties and lower mobility. In addition, the SHARE-created variable IADL (Instrumental Activities of Daily Living) is also used. It describes the number of limitations with several instrumental activities: preparing a hot meal, shopping for groceries, making telephone calls, taking medications, and managing money (such as paying bills). The IADL index ranges from $0-$ 5; A higher value of IADL indicates more functional limitations.

Lastly, we include a variable that captures cognitive skills: identifying animals. It is the number of animals that the individual listed in 60 seconds, in response to the question: "I would like you to name as many different animals as you can think of. You have one minute to do this."

\subsection{SAHS of natives and immigrants}

Figure 2 presents the distribution of raw (not controlled for differences in medical or any other socio-economic characteristics) SAHS levels for native-born and foreign-born individuals by their five possible responses. We illustrate the SAHS of immigrants by the three levels of duration since migration (up to $10 ; 11-20 ; 21$ and over). As it is evident from 
the histogram, the SAHS distribution among natives and immigrants follows a normal distribution. Few natives report poor health and even fewer report excellent health; the majority reports good health.

Similarly, within each YSM interval the distribution of the immigrant SAHS is normal. However, there are noticeable differences between individuals from the three YSM groups. During the first decade after arrival, the percentage of immigrants who report excellent SAHS (14 percent) is much larger compared to natives ( 7 percent) and compared to older arrivals. New arrivals have also the largest percentage for the 'good' and 'very good' categories. On the other hand, they constitute the lowest percentage in the 'poor' category ( 5 percent) and in the 'fair' category ( 14 percent).

Figure 2: Distribution of raw SAHS levels by nativity

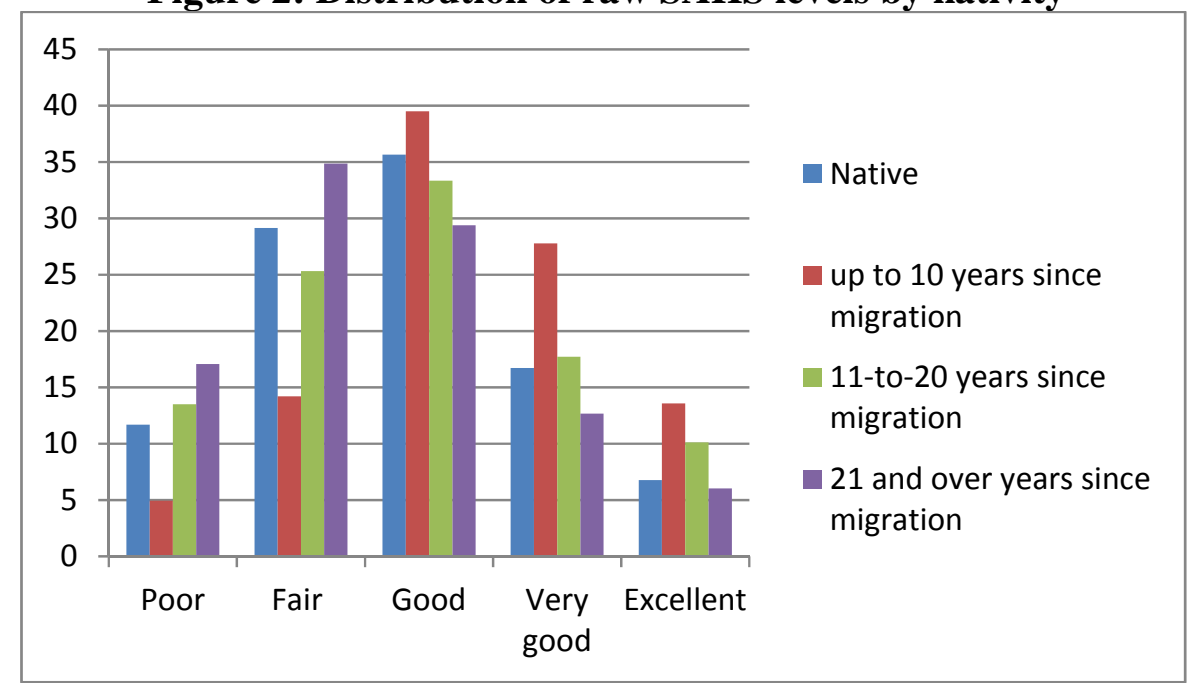

Note: Distributions based on SHARE waves 2004/5, 2006/7, 2011

With additional time in the host country, the reported SAHS of immigrants decreases. Immigrants with more than 21 years in the host country are the highest percentage reporting poor health (17 percent), more than those with 11-20 years since migration (13,5 percent) and more than natives (12 percent). This older cohort also has the lowest percentage in excellent SAHS (6 percent), lower than those with 11-20 years (10 percent) and lower than natives ( 7 percent). 


\subsection{Summary statistics}

We present the means and standard deviations of the variables of interest by nativity in Table 2. There are 38,762 natives and 4,275 immigrants. Immigrants as a whole have a slightly higher SAHS score (2.82) compared to natives (2.79), albeit their standard deviation is marginally higher.

The majority of our immigrant sample (72 percent) has been living in the host countries for more than 21 years. The most recent arrivals (less than 10 years) constitute 12 percent of the immigrant sample; 16 percent are between 11 and 20 years in the host country. The majority of immigrants also come from Europe (64 percent); the next largest origin continent is Africa (17 percent), followed by South America and Asia (9 percent), and lastly North America (1 percent). Clearly, immigrants come from countries with lower GDP per capita and there is wide variation among these countries.

Table 2: Summary statistics, natives and immigrants

\begin{tabular}{|c|c|c|}
\hline Characteristics & $\begin{array}{c}\text { Natives } \\
\text { Means (st.dev.) }\end{array}$ & $\begin{array}{c}\text { Immigrants } \\
\text { Means (st.dev.) }\end{array}$ \\
\hline SAHS (range of 1-5) & $2.79(1.07)$ & $2.82(1.08)$ \\
\hline \multicolumn{3}{|l|}{ Immigrants' Time in the Country (\%) } \\
\hline Up to $10 \mathrm{YSM}$ & - & 12.02 \\
\hline $11-20$ YSM & - & 16.12 \\
\hline 21 and over YSM & - & 71.86 \\
\hline \multicolumn{3}{|l|}{ Continent of origin } \\
\hline Europe & - & 63.97 \\
\hline Africa & - & 16.77 \\
\hline South America & - & 9.24 \\
\hline North America & - & 1.09 \\
\hline Asia & - & 8.91 \\
\hline \multicolumn{3}{|l|}{ Country Macroeconomics } \\
\hline Log. per capita GDP (host country) & $10.45(0.31)$ & $10.61(0.32)$ \\
\hline Log. per capita GDP (home country) & - & $9.47(1.09)$ \\
\hline Positive diff. bw home and host GDP & - & $0.49(0.16)$ \\
\hline Negative diff. bw home and host GDP & - & $1.19(1.01)$ \\
\hline \multicolumn{3}{|l|}{ Socio-economic variables } \\
\hline Male $(\%)$ & 46.08 & 42.74 \\
\hline \multicolumn{3}{|l|}{ Age in years $(\%)$} \\
\hline $50-60$ & 36.72 & 46.34 \\
\hline $61-70$ & 30.92 & 28.40 \\
\hline $71-80$ & 21.87 & 17.55 \\
\hline $81+$ & 10.49 & 7.71 \\
\hline Marital status (\%) & & \\
\hline
\end{tabular}




\begin{tabular}{|c|c|c|}
\hline Characteristics & $\begin{array}{c}\text { Natives } \\
\text { Means (st.dev.) }\end{array}$ & $\begin{array}{c}\text { Immigrants } \\
\text { Means (st.dev.) }\end{array}$ \\
\hline Married & 67.10 & 66.16 \\
\hline Widowed & 17.53 & 13.74 \\
\hline Single/divorced/separated & 15.37 & 20.10 \\
\hline Number of children in household & $2.04(1.42)$ & $2.23(1.61)$ \\
\hline Household income centile ( 1 to 10 ) & $5.35(2.95)$ & $5.03(2.95)$ \\
\hline \multicolumn{3}{|l|}{ Personal Medical variables } \\
\hline \multicolumn{3}{|l|}{ Health conditions: diagnosed with..(\%) } \\
\hline Heart problems & 12.18 & 10.74 \\
\hline Hypertension & 36.04 & 31.70 \\
\hline Cerebral vascular disease & 2.98 & 2.95 \\
\hline Diabetes & 12.79 & 15.61 \\
\hline Chronic lung disease & 6.41 & 5.89 \\
\hline Arthritis & 26.08 & 22.41 \\
\hline Osteoporosis & 1.93 & 2.19 \\
\hline Cancer & 5.03 & 5.95 \\
\hline Number of medical symptoms & $1.60(1.78)$ & $1.58(1.68)$ \\
\hline Drug use (number of drugs) & $1.52(1.69)$ & $1.42(1.60)$ \\
\hline Medical consultation (annual-number) & $7.29(10.20)$ & $7.60(12.04)$ \\
\hline Hospitalization $(\%)$ & 13.49 & 12.55 \\
\hline Quality of eyesight (range of 1-5) & $3.11(0.98)$ & $3.31(0.94)$ \\
\hline Alcohol consumption ( $>=5$ days $/$ week $)$ & 27.48 & 18.98 \\
\hline Obesity $(\mathrm{BMI}>30)$ & 19.24 & 17.87 \\
\hline IADL (range of 0-5) & $0.19(0.74)$ & $0.17(0.69)$ \\
\hline Mobility (range of 0-4) & $0.62(1.00)$ & $0.53(0.94)$ \\
\hline Number of remembered animals & $16.35(7.38)$ & $16.83(6.99)$ \\
\hline Height (in cm) & $166.35(8.88)$ & $166.31(9.35)$ \\
\hline \multicolumn{3}{|l|}{ Country shares in the sample $(\%)$} \\
\hline Austria & 5.11 & 8.50 \\
\hline Germany & 7.46 & 20.08 \\
\hline Sweden & 0.51 & 0.88 \\
\hline The Netherlands & 1.48 & 2.19 \\
\hline Spain & 30.33 & 18.56 \\
\hline Italy & 30.45 & 6.38 \\
\hline France & 9.79 & 26.08 \\
\hline Denmark & 0.62 & 0.36 \\
\hline Switzerland & 1.57 & 6.13 \\
\hline Belgium & 2.94 & 4.60 \\
\hline The Czech Republic & 2.29 & 1.68 \\
\hline Poland & 1.78 & 0.68 \\
\hline Hungary & 3.93 & 1.38 \\
\hline Portugal & 1.11 & 0.30 \\
\hline Slovenia & 0.37 & 0.78 \\
\hline Estonia & 0.25 & 1.40 \\
\hline \multicolumn{3}{|l|}{ Arrival years between } \\
\hline $1900-1940$ & - & 4.58 \\
\hline $1941-1950$ & - & 12.24 \\
\hline
\end{tabular}




\begin{tabular}{lccc}
\hline \hline Characteristics & & $\begin{array}{c}\text { Natives } \\
\text { Means (st.dev.) }\end{array}$ & $\begin{array}{c}\text { Immigrants } \\
\text { Means (st.dev.) }\end{array}$ \\
\hline \hline & $1951-1960$ & - & 11.80 \\
$1961-1970$ & - & 19.93 \\
$1971-1980$ & - & 15.26 \\
& $1981-1990$ & - & 10.83 \\
& $1991-2000$ & - & 16.51 \\
& $2000-2010$ & - & 8.84 \\
\hline \hline Sample Size & & 38,762 & 4,275 \\
\hline
\end{tabular}

Note: Based on three SHARE waves: 2004/5, 2005/6 and 2011

Our sample has fewer men than women, in general. The immigrant sample has a lower share of men (43 percent) than the native sample (46 percent). The age distribution is similar between the two groups, resembling a pyramid. However, there are differences within each age group. In the youngest age group (50-60) we find more immigrants (46 percent) than natives ( 37 percent). In the rest of the age groups, there are more natives than immigrants. Natives and immigrants are similar in the married status, but differ in the widowed category (fewer immigrants) and the single/divorced/separated category (fewer natives). While on average, both groups have two children in the household; immigrants have slightly more children (2.23) and a larger dispersion (1.61). Household income differs somewhat between immigrants and natives, with the latter belonging to a somewhat higher centile (5.35); this difference is significant.

Regarding diagnosed health conditions, Table 2 shows that a larger percentage of natives has been diagnosed with heart problems, hypertension, cerebral vascular disease, chronic lung disease, and arthritis. On the other hand, a larger percentage of immigrants have diabetes, osteoporosis (could be related to the older women in the sample) and cancer. All these are very much related to stress, unhealthy eating behaviors, as well as exposure to detrimental environmental elements (asbestos, etc.). An exception is hypertension that could also be stress related but is lower among immigrants. Studies have shown that immigrants are more likely to work in risky occupations that eventually take a toll on their health (Orenius and Zavodny, 2013; Giuntella, 2014).

Immigrants report fewer medical symptoms, lower drug use and hospitalization than natives. They also have better eyesight than natives and report much lower alcohol consumption. The latter could be related to cultural differences and the fact that our sample has more immigrant women than men. Alcohol is expensive and immigrants may not want 
or cannot afford to spend part of their budget in it. While, on average, natives and immigrants have similar height (average of $166 \mathrm{~cm}$ ), there is a wider variation among immigrants. Interestingly, we find a larger percentage of natives than immigrants in the obese category, indicating behavioral differences. The argument for immigrants lower obesity is that they come from poorer countries where they cannot afford being obese; they have no means to eat excessively and often work in hard manual jobs that require a lot of physical activity. Natives in more developed countries, on the other hand, are characterized by sedentary lifestyles, consumption of TV-dinners and fast-food that contribute to obesity.

When it comes to functional limitations, both groups have very few functional limitations. Yet, immigrants appear to be in much better shape than natives in IADL and mobility. Immigrants also score higher in the number of animals remembered and have a lower standard deviation than natives.

The majority of our immigrant sample resides in France, followed by Germany and Spain. In the native sample, Italy is mostly represented in the data, followed by Spain.

\section{Empirical analysis: Method}

The natural way to estimate a SAHS equation is by using Ordered Logit or Ordered Probit, since reported subjective-health is intrinsically ordinal (with 5 values from 1 to 5). However, as discussed in Ferrer-i-Carbonell and Frijters (2004), Frey and Stutzer (2002), and van Praag et al. (2010), when the dependent variable relates to satisfaction scores, the use of a linear model instead of an Ordered Logit model, does not change the basic results. ${ }^{9}$

Moreover, when data are clustered such as our individuals are in each host country, this design of the data needs to be taken into account when one conducts statistical analysis. Classical regression models fail to take into account the clustering nature of the data, potentially underestimating the standard errors and ultimately resulting in higher probabilities of Type I errors. Further, typical regression models do not allow for the estimation of between-country variation, which is usually different than the within-country variation.

\footnotetext{
${ }^{9}$ Oswald and $\mathrm{Wu}(2010)$, in their paper in Science, justify the use of OLS even when their dependent variable is a 4-category variable.
} 
We use multilevel regression analysis, which is a generalization of regression methods especially suitable when observations are clustered or nested. This method can best capture the clustering of individuals within countries and it can also best explore the variation within- and between-countries. Multilevel regression models are superior to OLS models because they allow controlling for group (country) random-effects. Traditional regression models control for group effects by including dummy variables for countries (Fixed-Effects Models). But in this case it is not possible to also include country-level macro variables due to collinearity.

In our analysis, health is a random variable that varies across countries. We compute the average health (SAHS) by country and then we define its distribution across all countries. The variance of this distribution indicates how much average health differs from country to country. When individuals are nested within countries this involves two levels of hierarchy: a within-country level and a between-country level. The country specific intercepts from the first level are treated as random variables at the second level. The country specific residuals in the second level model are called random effects and represent the country effects. The variance of these residuals indicates the impact of countries on health.

At the first level we run a series of within-country regressions to estimate SAHS, using a large set of personal medical and socio-economic characteristics as explanatory variables. This method is designed for clustered/nested observations (a group of individuals/observations in each host country) and allows for the inclusion of countryspecific macros (country-specific levels of the logarithm of per-capita GDP), in addition to country random-effects. Essentially, this model includes a specific country index (the constant term) and other country-specific parameters that describe the association between individuals' characteristics and health, for each country. As we focus on immigrants' SAHS, the equation includes dummy variables for immigrants (individuals who were not born in the current country of residence), with a distinction between different duration periods since migration, cohort and interview period effects. We add per-capita GDP (logarithm) in the country of residence as an explanatory variable.

The second level is the between-country regression. We estimate separate SAHS equations for the immigrant sample (with the same set of micro, medical and socio- 
economic variables). The country specific residuals (random-effects) at the second level describe the degree to which the average health of individuals in a specific country differs from those of the other countries, controlling for individual characteristics. Once the variance of the country effects is computed, we test for heterogeneity between countryeffects by determining the statistical significance of this variance. A significant variance indicates residualized differential country effects on health. ${ }^{10}$

We first look at the entire sample and compare immigrants to natives. In this exercise we estimate two specifications. The first includes only micro-level variables and the second is augmented by per-capita GDP (logarithm) of the country of residence. This exercise is tackling our question about the HIE.

Our examination of the immigrant sample involves three specifications. Here we deal with the question of altering immigrant health with additional time in the host country, as well as health differences by country of origin. The first specification contains the bare model with micro variables and age-cohort-period effects. We add per-capita GDP (logarithm) in the country of residence as an explanatory variable, controlling for random country-effects of the host countries because our main focus here is the macro effects of the host versus the sending countries. The logarithm of per-capita GDP of the host countries and the countries of origin are both included. The respective coefficients indicate whether the GDPs of the two reference points have similar or different effects in terms of sign and magnitude on the immigrants' evaluation of their health-status. Additionally, the effects of differences between these macros are analyzed in the third specification, distinguishing between positive and negative differences, and thus allowing for asymmetry.

\section{Results}

\subsection{Determinants of SAHS - comparing immigrants and natives}

Table 3 presents the results of the SAHS multilevel regression analysis for the entire sample. This regression method allows controlling for country effects and the inclusion of country-level variables (per-capita GDP), at the same time. A Likelihood Test comparing

\footnotetext{
${ }^{10}$ Since the country effects represent the deviation between a specific country's average health and the average health of the average country, their arithmetic mean is zero.
} 
OLS and multilevel regressions was conducted indicating that multilevel regression improves OLS $\left(\chi^{2}(1)=3668.4\right.$; p-value $\left.=0.000\right)$. We include a battery of medical and socio-economic explanatory variables and our core variables that relate to the immigration status (from YSM intervals). Natives are the reference group. Column (1) presents the results of the basic specification. Column (2) contains the results from the full model with the added GDP per capita. Results are similar in both columns.

As it is evident from Table 3, the net effect of the immigration status is not uniform and depends on duration in the receiving country. Compared to natives, immigrants who are in the host country for less than 10 years have significantly higher levels of SAHS, ceteris paribus. As immigrants stay longer in the host country the health effect disappears and immigrants' SAHS is not significantly different than that of natives. Immigrants with 11 to 20 YSM are less healthy than natives and those with more than 20 YSM are even more unhealthy. These findings indicate nonlinear health assimilation, albeit a negative one.

We find significant U-shaped aging effects on SAHS. All individuals over 60 have lower SAHS, compared to the 50 to 60 year olds. The pronounced nonlinearities show that while the 71 to 80 year olds are even more unhealthy than the 50 to 60 group the over 80 are not, maybe because the less healthy people over 80 have died. The period of arrival does not affect SAHS of immigrants, as is indicated by the insignificant coefficients of the cohort-of-arrival dummies, and the results are similar in the two specifications (in terms of magnitude and significance).

Table 3: Determinants of SAHS, immigrants and natives, multilevel regression

\begin{tabular}{lcc}
\hline Variables & & Coefficient (Std. Error) \\
\hline Immigrant status & Up to 10 YSM & $0.128(2.071)^{* *}$ \\
& 11 to 20 YSM & $-0.008(-0.057)$ \\
& 21 or more YSM & $-0.014(-0.072)$ \\
Arrival years between & natives & Ref. \\
& $1900-1940$ & $0.222(1.068)$ \\
& $1941-1950$ & $0.062(0.314)$ \\
$1951-1960$ & $0.065(0.331)$ \\
& $1961-1970$ & $0.004(0.020)$ \\
& $1971-1980$ & $-0.009(-0.046)$ \\
& $1981-1990$ & $-0.005(-0.025)$ \\
& $1991-2000$ & $-0.021(-0.160)$ \\
& $2001-2010$ & Ref. \\
\hline Age (years) & $61-70$ & $-0.028(-3.020)^{* * *}$
\end{tabular}




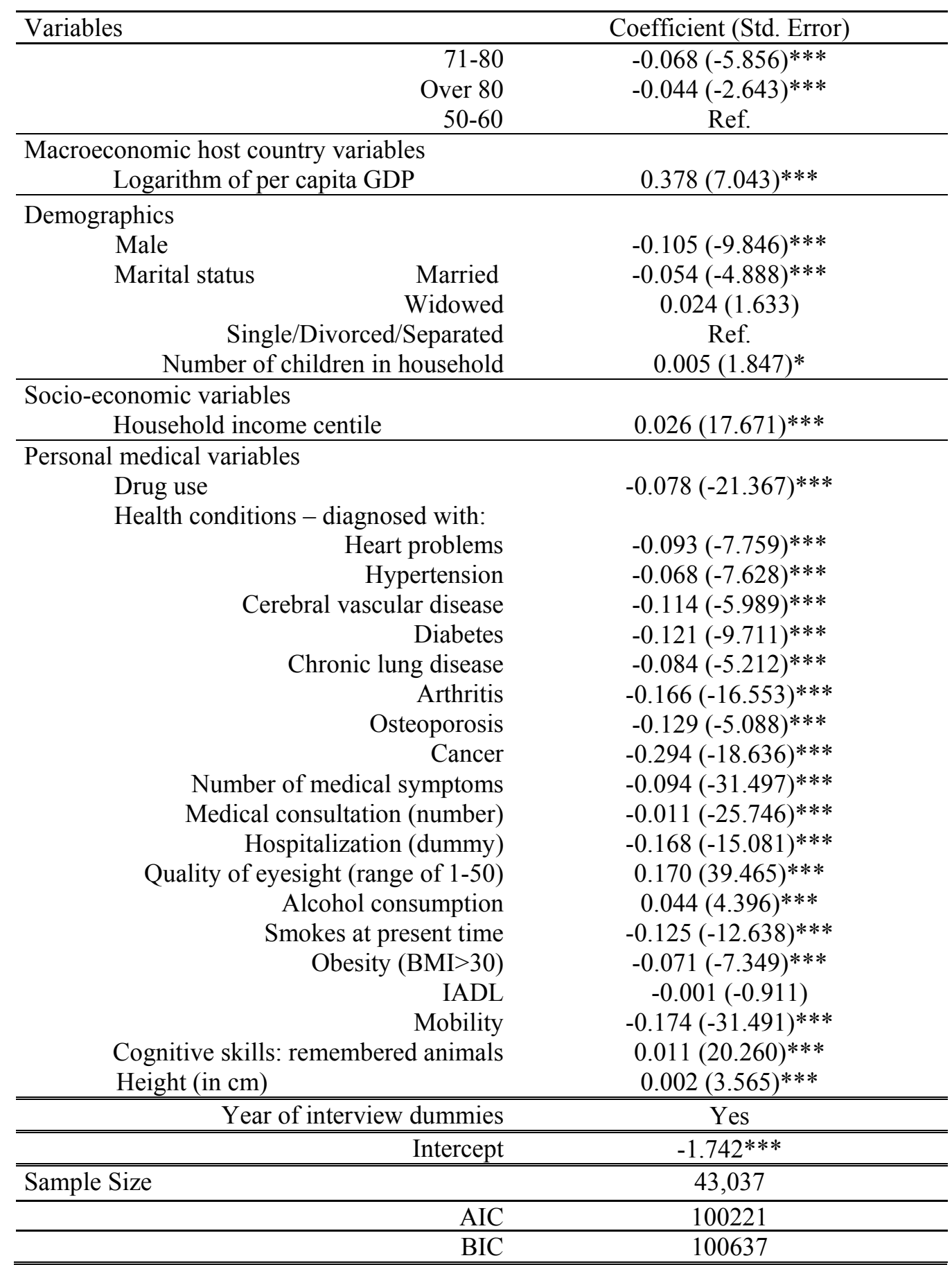

Note: Based on pooled data from SHARE waves of 2004/5, 2006/7 and 2011

${ }^{*} \mathrm{p}<10 \% ; * \mathrm{p}<5 \% ; * * * \mathrm{p}<1 \%$

As expected, the coefficient of GDP is positive and highly significant, meaning that individuals residing in countries with higher GDP per capita have higher SAHS, ceteris paribus. This positive effect could stem from omitted variables (e.g., nutrition, quality of 
health-services) that are correlated with GDP and are therefore captured by the GDP variable. Another explanation is that a more positive reference-point (higher country-GDP) per-se leads to an increase in the subjectively-reported SAHS.

Men report lower SAHSs than women; the result is significantly different than zero. This could stem from gender-specific genetic differences not captured by other variables, or because men are more sensitive to health issues than women; it is also known that women have a longer life expectancy. It is also possible that the gender result is related to employment. Immigrant men over 50 are still part of the labor force, while women may stay home and be shielded from labor market stress.

While married individuals have significantly lower SAHS than those who are single, divorced or separated, those having a higher number of children in the household have a significantly higher SAHS. We attempt to explain these results through the happiness literature, which finds similar results. Married individuals may be subjected to the health of the partner and face additional stress. However, having children has an appeasing and healing effect. This variable may pick up the warmth and completeness that a family provides to one's life. Also, parents feel that they have to be well and healthy to take care of their children and because being around children makes them feel better, perhaps due to indirect rejuvenating effects of youth. Lastly, being in a higher income centile has a positive and significant effect on SAHS.

Medical conditions have the expected effects. Drug use, smoking, obesity, and all negative health conditions have a negative effect on SAHS. Good eyesight, being taller and having good cognitive skills, on the other hand, have positive effects on SAHS. Interestingly, alcohol consumption has also a positive effect on SAHS. Functional limitations of mobility have a negative effect on health; the coefficient on IADL is not significant, however.

\subsection{Determinants of SAHS - comparing immigrant groups}

Table 4 refers to the determinants of SAHS within the immigrant sample. In our multilevel regressions the grouping is by the receiving countries (16 countries). The three columns present the results of the different specifications as we add the macro variables. Results are contained in Columns (1) and (2). In Column (1), we introduce macros for the 
sending and the receiving countries, as well as their per-capita GDP (logarithm). In order to obtain more insight into the differential effects of the level of development of the sending and receiving countries, we include differences between the logarithm of home and host country per-capita GDPs in Column (2). We include the two variables for positive difference between origin and receiving country GDPs (country of origin more developed) and negative difference between origin and receiving country GDPs (home country less developed). The first difference is equal to the difference between the logarithms of GDP in origin and receiving countries, if this difference is positive, and zero otherwise. The second one is equal to the absolute value of the difference between origin- and host country GDPs (logarithm) if this difference is negative, otherwise it is equal zero. Different coefficients of these two variables indicate asymmetry in the effects of positive and negative deviations. Interestingly, results in all three columns are very similar.

Controlling for age-cohort and period of interview effects, Table 4 presents the results for immigrants only. Due to collinearity problems among the variables YSM, cohort, and interactions we ran the specification with interactions. Results clearly indicate that additional YSM in the host country have a significant and negative effect on the health status of immigrants, beyond any aging affects. Specifically, compared to the newcomers (less than 10 YSM), immigrants who arrived in the current country of residence more than 10 years ago report significantly lower levels of SAHS. This result is robust across all specifications and confirms important non-linearities. SAHS deteriorates for immigrants who reside in the host country more than one decade. The rate of deterioration is somewhat different for different cohorts-of-arrival, but the general pattern clearly indicates health deterioration as immigrants stay longer in the receiving country. However, there no significant aging effects on the health status of immigrants, ceteris paribus.

Table 4: Determinants of SAHS, immigrant sample, multilevel regressions

\begin{tabular}{|c|c|c|}
\hline Variables & Model 1 & Model 2 \\
\hline \multicolumn{3}{|l|}{ Immigrant status } \\
\hline Up to $10 \mathrm{YSM}$ & Ref. & Ref. \\
\hline \multicolumn{3}{|l|}{11 to $20 \mathrm{YSM}$} \\
\hline Arrival years between 1981-1990 & $-0.100(-0.735)$ & $-0.097(-0.713)$ \\
\hline $1991-2000$ & $-0.160(-2.142)^{* *}$ & $-0.160(-2.139)^{* *}$ \\
\hline \multicolumn{3}{|l|}{21 or more YSM } \\
\hline Arrival years between 1900-1940 & $-0.030(-0.318)$ & $-0.026(-0.273)$ \\
\hline $1941-1950$ & $-0.142(-2.145)^{* *}$ & $-0.140(-2.115)^{* *}$ \\
\hline
\end{tabular}




\begin{tabular}{|c|c|c|}
\hline $\begin{array}{l}1951-1960 \\
1961-1970 \\
1971-1980 \\
1981-1990\end{array}$ & $\begin{array}{l}-0.130(-2.051)^{* *} \\
-0.175(-2.845)^{* * *} \\
-0.179(-2.916)^{* * *} \\
-0.161(-2.389)^{* *}\end{array}$ & $\begin{array}{l}-0.131(-2.068)^{* *} \\
-0.178(-2.883)^{* * *} \\
-0.181(-2.949)^{* * *} \\
-0.162(-2.410)^{* *}\end{array}$ \\
\hline $\begin{array}{r}61-70 \\
71-80 \\
\text { Over } 80 \\
50-60 \\
\end{array}$ & $\begin{array}{l}-0.038(-1.208) \\
-0.018(-0.480) \\
0.003(0.053) \\
\text { Ref. } \\
\end{array}$ & $\begin{array}{c}-0.037(-1.184) \\
-0.020(-0.520) \\
0.001(0.011) \\
\text { Ref. } \\
\end{array}$ \\
\hline $\begin{array}{l}\text { Macroeconomic country variables } \\
\text { Log. of per capita GDP (host country) } \\
\text { Log. of per capita GDP (homecountry) }\end{array}$ & $\begin{array}{c}0.325(4.181)^{* * *} \\
0.041(2.089)^{* *}\end{array}$ & $0.358(4.515)^{* * *}$ \\
\hline $\begin{array}{l}\text { Positive diff. (origin - host GDPs) } \\
\text { Negative diff (origin - host GDPs) }\end{array}$ & - & $\begin{array}{r}-0.414(-3.609)^{* * *} \\
0.309(3.822)^{* * *}\end{array}$ \\
\hline $\begin{array}{l}\text { Demographics } \\
\text { Male }\end{array}$ & $-0.098(-3.003)^{* * *}$ & $-0.098(-3.009)^{* * *}$ \\
\hline $\begin{array}{c}\text { Marital status } \begin{array}{r}\text { Married } \\
\text { Widowed }\end{array} \\
\text { Single/Divorced/Separated }\end{array}$ & $\begin{array}{c}-0.068(-2.028)^{* *} \\
-0.007(-0.167) \\
\text { Ref. }\end{array}$ & $\begin{array}{c}-0.069(-2.049)^{* *} \\
-0.008(-0.177) \\
\text { Ref. }\end{array}$ \\
\hline $\begin{array}{l}\text { Number of children in household } \\
\text { Socio-economic variables } \\
\text { Household income centile }\end{array}$ & $0.030(6.597)^{* * *}$ & $0.030(6.596)^{* * *}$ \\
\hline $\begin{array}{l}\text { Personal medical variables } \\
\text { Drug use }\end{array}$ & $-0.085(-7.888)^{* * *}$ & $-0.086(-7.914)^{* * *}$ \\
\hline $\begin{array}{r}\text { Health conditions - diagnosed with: } \\
\text { Heart problems } \\
\text { Hypertension } \\
\text { Cerebral vascular disease } \\
\text { Diabetes } \\
\text { Chronic lung disease } \\
\text { Arthritis } \\
\text { Osteoporosis } \\
\text { Cancer }\end{array}$ & $\begin{array}{c}-0.057(-1.633) \\
-0.063(-2.328)^{* *} \\
0.002(0.029) \\
-0.184(-4.998)^{* * *} \\
-0.064(-1.431) \\
-0.146(-5.014)^{* * *} \\
-0.277(-3.151)^{* * *} \\
-0.199(-4.095)^{* * *}\end{array}$ & $\begin{array}{c}-0.057(-1.626) \\
-0.063(-2.302)^{* *} \\
0.001(0.020) \\
-0.184(-4.987)^{* * *} \\
-0.064(-1.429) \\
-0.146(-5.038)^{* * *} \\
-0.277(-3.152)^{* * *} \\
-0.201(-4.127)^{* * *}\end{array}$ \\
\hline Number of medical symptoms & $-0.071(-8.150)^{* * *}$ & $-0.071(-8.138)^{* * *}$ \\
\hline Medical consultation (number) & $-0.012(-9.141)^{* * *}$ & $-0.012(-9.092)^{* * *}$ \\
\hline $\begin{array}{l}\text { Hospitalization (dummy) } \\
\text { Quality of eyesight (range of } 1-50 \text { ) }\end{array}$ & $-0.115(-3.377)^{* * *}$ & $\begin{array}{l}-0.115(-3.362)^{* * *} \\
0.172(12520)^{* * *}\end{array}$ \\
\hline Alcohol consumption & $0.088(2.506)^{* *}$ & $0.087(2.470)^{* *}$ \\
\hline Smokes at present time & $-0.149(-5.006)^{* * *}$ & $-0.149(-5.017)^{* * *}$ \\
\hline Obesity $(\mathrm{BMI}>30)$ & $-0.041(-1.413)$ & $-0.041(-1.432)$ \\
\hline IADL & $-0.019(-0.911)$ & $-0.019(-0.939)$ \\
\hline Mobility & $-0.159(-9.356)^{* * *}$ & $-0.159(-9.357)^{* * *}$ \\
\hline Cognitive skills: remembered animals & $0.015(8.509)^{* * *}$ & $0.015(8.512)^{* * *}$ \\
\hline Height $(\mathrm{cm})$ & $0.003(1.849) *$ & $0.003(1.888)^{*}$ \\
\hline $\begin{array}{r}\text { Africa } \\
\text { South America } \\
\text { North America } \\
\text { Asia } \\
\text { Europe }\end{array}$ & $\begin{array}{c}0.062(0.938) \\
-0.111(-1.255) \\
0.455(3.199)^{* * *} \\
0.183(3.136)^{* * *} \\
\text { Ref. }\end{array}$ & $\begin{array}{c}0.073(1.077) \\
-0.110(-1.249) \\
0.455(3.199)^{* * *} \\
0.194(3.272)^{* * *} \\
\text { Ref. }\end{array}$ \\
\hline Year of interview dummies & Yes & Yes \\
\hline
\end{tabular}




\begin{tabular}{rcc}
\hline Sample Size & 4,275 & 4,275 \\
\hline AIC & 9776 & 9777 \\
\hline BIC & 10100 & 10108 \\
\hline \hline
\end{tabular}

Note: Based on pooled data from SHARE waves of 2004/5, 2006/7 and 2011

$* \mathrm{p}<10 \% ; *$; $<5 \% ; * * \mathrm{p}<1 \%$

Columns (1) and (2) show that the per capita GDP of the two reference countries, the country of origin and the current host country, have positive and significant effects on SAHS, but the host country's GDP seems to have a much more pronounced effect. ${ }^{11} \mathrm{We}$ offer some speculations: living in a more developed country (before migration) could result in better health later on in life (due to better nutrition, vaccination, preventive health systems, etc.). As we hypothesized before, a strong positive health selection may also be at play. Immigrants from less developed countries have to go through many more hurdles and deal with uncertainty. The survivors of the move are thus healthier physically and mentally.

Column (2) adds more insight on the differential effects of the sending and receiving countries, by splitting the differences between the GDPs into positive and negative differences, allowing for asymmetry around the no-difference point. This is done by using variables of positive deviations (between home and host countries) and absolute negative deviations, in addition to the home country GDP. As the results indicate, an increase in a positive deviation (the home country is more developed than the host country) leads to a decrease in the immigrants' SAHS, while an increase in the absolute negative deviation leads to an increase in their SAHS. It therefore appears that positive and negative deviations have different impacts on individual SAHS.

The coefficients of the rest of the controls are as expected, and similar to the effects revealed for the whole sample in Table 3. Males have lower SAHS than females. This could be because of genetic differences not captured by other variables or because men are more sensitive to health issues than women, or as we discussed in Table 3, the gender result is related to employment. Being married has again a negative and significant effect on health, ceteris paribus. Unlike Table 3, the number of children in the household bear no significant effect on the health status of immigrants. The higher percentile of household income has a positive and significant effect on SAHS. This could be because more wealthy ${ }^{11}$ While health is not identical to well-being, our result is different than the Akay, Bargain and Zimmermann
(2013), who found a negative effect of home country GDP on immigrant well-being. 
immigrants can invest in preventive care, they can afford better care, or they know that if they get sick they will be able to have good care.

The country of origin variables indicate that differences in SAHS vary among immigrants. Immigrants from North America and Asia have higher SAHS than immigrants from Europe (the reference group) in all specifications. Immigrants from South America and Africa are not different than those from Europe.

Results on the medical variables confirm that for immigrants too medical conditions, symptoms, and hospitalizations have a strong negative effect on SAHS; so does smoking and drug use. Good eyesight has a positive effect. Similar to Table 3, we find that alcohol consumption has a positive effect on SAHS. A possible explanation could stem from culture. Non-European immigrants come from countries that either do not drink or drink among family and friends as a celebratory custom that also bonds people. If immigrants have this positive stance towards drinking, then drinking can have a positive psychological effect that manifests itself in SAHS.

Naturally, good cognitive abilities affect health positively. Remembering animals and thus having a sharp mind has a positive effect on SAHS. Functional limitations on the other hand, take their toll on SAHS. Lastly, taller immigrants report higher health status.

Overall, these results show that even after we control for a multitude of medical conditions, demographics, behavioral changes, age, cohort and period of interview, the health status of immigrants deteriorates the longer they stay in the host country. This is in congruence with previous studies in other countries. A plausible explanation is psychological. Middle-aged immigrants and older immigrants who are still in the host country may feel severed from their origins and perceive a lower health status. Missing one's country of origin, especially the image one has kept in their mind from growing up, the different geographic settings and climate can have a negative subconscious effect. Another explanation could be related to unobserved environmental factors in the host countries. A third potential explanation could be the reference group immigrants compare themselves to. For example, when immigrants first arrive it is natural to compare themselves to their countrymen back home. After they reside in the host country, natives can be their reference group. If natives are in better health, immigrants may report a comparatively lower health status, even if their actual health has not changed. However, 
when we tested this hypothesis by pulling the sample of immigrants and natives together we did not find evidence of this explanation.

\section{Concluding Remarks}

In this study we were set to analyze the determinants of self-assessed health status (SAHS) of immigrants over the age of 50 in Europe and compare them to natives. Studying the health of individuals over 50 is important because health starts deteriorating around the age of 50. A better understanding of the health of immigrants is essential and of great socio-political importance. It can provide insights about the origins of health disparities in a country and allow us to better address public health challenges. A better understanding of the immigrants' health status, behavior, and attitudes is needed in order to better cater to their needs and integration. A population with compromised health can burden the health care and welfare systems of the country.

We examine both micro and macro determinants of health. We are also interested in any possible changes in SAHS as immigrants stay longer in the host country and in comparing them to natives. For this study, we utilize a unique and rich dataset, the Survey of Health, Aging and Retirement in Europe (SHARE). We augment our data with information on macroeconomic variables from the home and host countries. Our sample contains men and women over the age of fifty, originating from twenty-two different countries of origin and residing in sixteen European host countries between 2003 and 2011. In our empirical analysis we are pulling the three available cross-sections together. Because of the clustering of individuals within countries, we use a multilevel analysis that allows us to explore both within- and between-country variation.

Our descriptive statistics show that SAHS of both immigrants and natives follows a normal distribution. There are a few individuals reporting poor health, a few reporting excellent health and the bulk of individuals report good health. However, there are differences between the two groups and especially there are differences among immigrants by YSM in the host country. In essence we find that there is a healthy immigrant effect.

Our results about the entire sample of natives and immigrants indicate that upon arrival in the host country immigrants' health is significantly better than the health of their 
native-born counterparts. With additional years of residence in the host country their health gradually deteriorates, converges to that of the natives or even falls below it.

The more novel finding relates to the macro effects of the development levels of both the country of origin and the host country - the GDPs of the two reference countries have positive effects on the individual's perceived-health (SAHS). However the effect of the host country's GDP is much more pronounced.

It appears that positive and negative deviations in GDP have different impacts on individual SAHS. These differential effects can be explained as some variant of the LossAversion Theory (Kahneman and Tversky, 1979): A positive deviation means that the immigrant suffered from some 'loss' when he left his country of origin and immigrated to a less developed country. A negative deviation represents a 'gain' for the immigrant. The Loss-Aversion Theory claims that 'losses' are valued more than same-size 'gains', and this is precisely what our results indicate.

Our results indicate that the immigration status (and duration) and macros of the sending and receiving countries have significant effects on the individual's SAHS. However, the mechanisms still need to be explored. The mechanism is most probably determined by the nature of the variable under discussion (e.g., health versus well-being). Our results pertain to a sub-population in the sixteen EU countries under study, that of the over 50 years of age. However, the older age group is more relevant when health is evaluated and examined for its determinants. Around this age health starts to deteriorate and policies/budgets/programs that aim at catering to residents' (including immigrants) health need to become more important and urgent. 


\section{References}

Abraido-Lanza, A.F., Chao, M.T. and Florez, K.R. (2005), "Do Healthy Behaviors Decline with Greater Acculturation? Implications for the Latino Mortality Paradox", Social Science and Medicine 61: 1243-1255.

Acevedo-Garcia, D., Pan, J., Jun H.J., Osypuk, T.L. and Emmons, K.M. (2005), "The Effect of Immigrant Generation on Smoking”, Social Science and Medicine 61: 1223-1242.

Akay, A, Bargain, O, and Zimmermann K.F. (2013), "Home Sweet Home? Macro-economic Conditions in Home Countries and the Well-Being of Migrants", IZA Discussion Paper No. 7862. Bonn.

Antecol, H. and Bedard, K. (2006), "Unhealthy Assimilation: Why Do Immigrants Converge to American Health Status Levels?” Demography 43(2):337-360.

Averett, S.L., Argys, L.M. and Kohn, J.L. (2012), "Immigration, Obesity and Labor Market Outcomes in the UK", IZA Journal of Migration, 1:2, 1-19.

Bentham, G. (1988), Migration and Morbidity: Implications for Geographical Studies of Disease", Social Science and Medicine 26(1): 49-54.

Benyamini, Y. and Idler E.L. (1999), "Community Studies Reporting Association between Self-Rated Health and Mortality: Additional Studies, 1995-1998", Research on Aging 21: 392-401.

Biddle, N., Kennedy, S. and McDonald, J.T. (2007), "Health Assimilation Patterns amongst Australian Immigrants", Economic Record 83: 16-30.

Carrasco-Garrido, P., De Miguel, A.G., Barrera, V.H. and Jimenez-Garcia, R. (2007), "Health Profiles, Lifestyles and Use of Health Resources by the Immigrant Population Resident in Spain", European Journal of Public Health 17(5): 503-507.

Cesari, M., Pahor, M., Marzetti, E., Zamboni, V., Colloca, G., Tosato, M., Patel, K.V., Tovar, J.J. and Markides K. (2009), "Self-Assessed Health Status, Walking Speed and Mortality in Older MexicanAmericans", Gerontology 55(2): 194-201.

Chiswick, B.R., Lee, Y.L. and Miller P.W. (2008), "Immigrant Selection Systems and Immigrant Health", Contemporary Economic Policy 26(4): 555-578.

Courbage, Y. and Khlat, M. (1996), "Mortality and Causes of Death of Moroccans in France, 1979-91", Population 8: 59-94.

Deaton, A. and Paxson, C.H. (1998), "Aging and Inequality in Income and Health", American Economic Review, Papers and Proceedings 88: 248-253.

Delaney, L., Fernihough, A. and Smith, J.P. (2013), "Exploring Poor Health: The Irish in England", Demography 50: 2013-2035

Eurostat (2013), Population on January $1^{\text {st }}$ 2013, by Five-Year Age Groups and Sex. Can be accessed at: http://epp.eurostat.ec.europa.eu/portal/page/portal/eurostat/home.

Evans, J. (1987), "Migration and Health", International Migration Review 21(3): v-xiv.

Fenelon, A. (2013), "Revisiting the Hispanic Mortality Advantage in the United States: The Role of Smoking", Social Science and Medicine 82: 1-9.

Ferrer-i-Carbonell, A. and Frijters, P. (2004), "How Important Is Methodology for the Estimates of the Determinants of Happiness?” The Economic Journal 114, 641-659.

Frey, B.S. and Stutzer, A. (2002), Happiness and Economics. How the Economy and Institutions Affect Wellbeing. Princeton: New Jersey: Princeton University Press.

García-Muñoz, T., Neuman, S. and Neuman T. (2014a), "Subjective Health Status of the Older Populations: Is it Related to Country-Specific Economic Development Measures?” Working Paper No. 2014-02, Department of Economics, Bar-Ilan University.

Garcia-Munoz, T., Neuman, S. and Neuman, T. (2014b), "Health Risk Factors among the Older European Populations: Personal and Aggregate Country Effects", paper presented in the $6^{\text {th }}$ Annual Meeting on the Economics of Risky Behaviors (AMERB): Medellin, Colombia, May 8-10.

Grove, N. and Zwi, A. (2006), "Our Health and Theirs: Forced Migration, Othering, and Public Health", Social Science and Medicine 62: 1931-1942.

Guintella, O. and Mazzonna, F. (2014), “Do Immigrants Bring Good Health?” IZA, Bonn: Discussion Paper No. 8073.

Guintella, O. (2013), "Why Does the Health of Immigrants Deteriorate? Evidence from Birth Records", IZA, Bonn: Discussion Paper No. 7588. 
Idler, E.L. and Benyamini, Y. (1997), "Self-Rated Health and Mortality: A Review of Twenty-Seven Community Studies", Journal of Health and Social Behavior 38(1): 21-37.

Jasso, G., Massey, D.S., Rosenzweig, M.R. and Smith, J. (2004), "Immigrant Health: Selectivity and Acculturation". In: Anderson N.B., Bulatao, R.A. and Cohen, B. (eds.), Critical Perspectives on Racial and Ethnic Differences in Health in Late Life (pp. 227-266). Washington, DC: National Academies Press.

Kahneman, D. and Tversky, A. (1979), "Prospect Theory: An Analysis of Decision under Risk", Econometrica 47: 263-291.

Kasl, S.V. and Berkman, L. (1983), "Health Consequences of the Experience of Migration", Annual Review of Public Health 4: 69-70.

Kennedy, S., McDonald, J.T. and Biddle, N. (2006), "The Healthy Immigrant Effect and Immigrant Selection: Evidence from Four Countries", Canada: Ontario, SEDAP Research paper No. 164. Available at: http://socserv.mcmaster.ca/sedap/p/sedap164.pd

Lara, M.I., Gamboa, C., Kahramanian, M.I., Morales, L.S., and Bautista, D.E. (2005), "Acculturation and Latino Health in the United States: A Review of the Literature and its Sociopolitical Context", Annual Review of Public Health 26: 367-397.

Markides, K.S., Salinas, J. and Sheffield, K. (2008-2009), “The Health of Older Immigrants”, Generations 32(4): 46-52.

Marmot, M.G., Adelstein, A.M. and Bulusu, L. (1984), "Lessons from the Study of Immigrant Mortality", The Lancet, June: 1455-1457.

Marmot, M.G. and Syme, S.L. (1976), “Acculturation and Coronary Heart Disease in Japanese-Americans”, American Journal of Epidemiology 104(3): 225-247.

Mora, P.A., Di’Bonaventura, M.D., Idler, E., Leventhal, E. and Leventhal, H. (2008), "Psychological Factors Influencing Self-Assessments of Health: Toward an Understanding of the Mechanisms Underlying How People Rate Their Own Health", Annals of Behavioral Medicine 36: 292-303.

Mossey, J.M. and Shapiro, E. (1982), "Self-Rated Health: A Predictor of Mortality among the Elderly", American Journal of Public Health 72(8): 800-808.

Neuman, S. (2005), "Aliya to Israel: Immigration under Conditions of Adversity". In (Zimmermann, K.F., (ed.) European Migration: What Do We Know? Oxford University Press, pp. 459-506.

Neuman, S. (2014), “Are Immigrants Healthier than Native Residents?”, IZA World of Labor (accessible at http://wol.iza.org).

Newbold, K.B. (2005), "Self-Rated Health within the Canadian Immigrant Population: Risk and the Healthy Immigrant Effect", Social Science and Medicine 60: 1359-1370.

Oswald, A.J. and Wu, S. (2010), "Objective Confirmation of Subjective Measures of Human Well-Being: Evidence from the U.S.A." Science 327(5965): 576-579.

Orrenius, P.M. and Zavodny, M. (2009), "Do Immigrants Work in Riskier Jobs?” Demography 46(3): 535551.

Orrenius, P.M. and Zavodny, M. (2013), “Immigrants in Risky Occupations?”. In: Constant and Zimmermann (eds), International Handbook on the Economics of Migration (pp. 214-226). Edward Elgar Publishing.

Palloni, A. and Arias, E. (2004), "Paradox Lost: Explaining the Hispanic Adult Mortality Advantage", Demography 41(3): 385-415.

Palloni, A. and Ewbank, D. (2004), "Selection Process in the Study of Racial and Ethnic Differences in Adult Health and Mortality". In: Anderson N.B., Bulatao, R.A. and Cohen, B. (eds.), Critical Perspectives on Racial and Ethnic Differences in Health in Late Life (pp. 171-226). Washington, DC: National Academies Press.

Pew Research Center Report (2011), The Future of the Global Moslem Population: Projections for 20102030. Washington.

Rechel, B., Mladovsky, P., Deville, W., Rijks, B., Petrova-Benedict, R. and McKee, M. (eds.) (2011), Migration and Health in the European Union, The Open University Press, UK: European Observatory on Health Systems and Policies Series.

Ronellenfitsch, U. and Razum, O. (2004), "Deteriorating Health Satisfaction among Immigrants from Eastern Europe to Germany," International Journal for Equity in Health - an Open Access Journal (can be accessed at: http://www.equityhealthj.com/content/3/1/4).

Sen, A. (2002), “Health: Perception versus Observation”, British Medical Journal 324(13): 860-861. 
Smith, J.P. (1999), "Healthy Bodies and Thick wallets: The Dual Relation between Health and Economic Status", Journal of Economic Perspectives 13: 145-166.

Sole-Auro, A. and Crimmins, E.M. (2008), "Health of immigrants in European Countries", International Migration Review 42(4): 861-876.

United Nations, Department of Economic and Social Affairs, Population Division (2013). International Migration, - The 2013 Revision.

Van Praag, B.M.S. and Ferrer-i-Carbonell, A. (2008), "Happiness Quantified. A Satisfaction Calculus Approach", Oxford University Press, New York.

VandenHeuvel, A. and Wooden, M. (1999), New Settlers have their Say - How Immigrants Fare over the Early Years of Settlement. Canberra, Australia: Department of Immigration and Multicultural Affairs.

Viruell-Fuentes, E. (2007), "Beyond Acculturation: Immigration, Discrimination, and Health Research among Mexicans in the United States", Social Science and Medicine 65: 1524-1535.

WHO (2010), Health of Migrants - The Way Forward, Report of a global consultation, Madrid, Spain, 3-5 March 2010. Geneva: World Health Organization.

Zavodny, M. (2014), "Do Immigrants Work in Worse Jobs than U.S. Natives? Evidence from California", IZA, Bonn: Discussion Paper No. 8327. 